\title{
The contribution of Escherichia coli from human and animal sources to the integron gene pool in coastal waters
}

\author{
Alexandra Moura *, Susana Araújo, Marta S. Alves, Isabel Henriques, Anabela Pereira and \\ António C. M. Correia
}

Department of Biology and CESAM, University of Aveiro, Aveiro, Portugal

\author{
Edited by: \\ Elisabeth Grohmann, University \\ Medical Centre Freiburg, Germany \\ Reviewed by: \\ Carmen Torres, University of Rioja, \\ Spain \\ María Del Pilar Garcillán-Barcia, \\ Universidad de Cantabria, Spain \\ *Correspondence: \\ Alexandra Moura, Department of \\ Biology and CESAM, University of \\ Aveiro, Campus Universitário de \\ Santiago, 3810-193 Aveiro, Portugal \\ e-mail:amoura@ua.pt
}

To understand the contribution of animal- and human-derived fecal pollution sources in shaping integron prevalence and diversity in beach waters, 414 Escherichia coli strains were collected from beach waters (BW, $n=166)$, seagull feces (SF, $n=179$ ), and wastewaters (WW, $n=69$ ), on the World Biosphere Reserve of the Berlenga Island, Portugal. Statistical differences were found between the prevalence of integrons in BW (21\%) and WW (10\%), but not between BW and SF (19\%). The majority of integrase-positive $\left(\right.$ int $\left.^{+}\right)$-strains affiliated to commensal phylogroups B1 (37\%), A0 (24\%), and A1 (20\%). Eighteen different gene cassette arrays were detected, most of them coding for resistances to aminoglycosides, trimethoprim, chloramphenicol, and quaternary ammonia compounds. Common arrays were found among strains from different sources. Multi-resistance to three or more different classes of antibiotics was observed in 89, 82, and $57 \%$ of int ${ }^{+}$-strains from BW, SF and WW, respectively. Plasmids were detected in $79 \%$ of strains (60/76) revealing a high diversity of replicons in all sources, mostly belonging to IncF (Frep, FIA, and FIB subgroups), Incl1, IncN, IncY, and IncK incompatibility groups. In 20\% (15/76) of strains, integrons were successfully mobilized through conjugation to E. coli CV601. Results obtained support the existence of a diverse integron pool in the E. coli strains from this coastal environment, associated with different resistance traits and plasmid incompatibility groups, mainly shaped by animal fecal pollution inputs. These findings underscore the role of wild life in dissemination of integrons and antibiotic resistance traits in natural environments.

\footnotetext{
Keywords: environmental reservoirs, microbial risk assessment, multi-resistance, integron diversity, replicon typing, Enterobacteriaceae
}

\section{INTRODUCTION}

Environmental antibiotic resistance reservoirs are known to represent the origins of the resistance determinants that nowadays constitute major clinical threats (Davies and Davies, 2010; Tacão et al., 2012, 2013; Perry and Wright, 2013). In the recent years much attention has been given to marine environments and migratory birds with increasing evidence of their role in the dissemination of antibiotic resistant Enterobacteriaceae, particularly Escherichia coli (Dolejska et al., 2007, 2009; Poeta et al., 2008; Radhouani et al., 2009; Poirel et al., 2012; Hernandez et al., 2013; Kmet et al., 2013; Santos et al., 2013; Veldman et al., 2013). E. coli is the predominant facultative anaerobe in gastrointestinal tract of humans and animals (Tenaillon et al., 2010). Although most E. coli are commensal, some can be pathogenic and may be transmitted through contaminated water or food, or through contact with animals and people. Pathogenic E. coli has been reported as a major cause of mortality as a result of infant diarrhea, extra-intestinal and urinary tract infections, thus constituting an important hospital- and community-acquired pathogen (Guentzel, 1996; Touchon et al., 2009). Due to their genetic flexibility and adaptability to diverse stress conditions, both commensal and pathogenic E. coli strains have the ability to persist in terrestrial and aquatic habitats (Van Elsas et al., 2011).

Integrons are bacterial site-specific recombination platforms of acquisition and expression of mobile genes, called gene cassettes (Stokes and Hall, 1989). It has been shown that the persistence of antibiotics in the environment at sub-therapeutic concentrations contributes to the acquisition of antibiotic resistance genes between different strains, mediated by integrons, as a result of the activation of bacterial SOS responses (Baharoglu et al., 2010; Andersson and Hughes, 2011). In addition, integrons are often associated with conjugative plasmids which contribute to their mobilization and wide dissemination (Moura et al., 2012a). The spread of such determinants can constitute serious environmental risks, compromising both ecosystem and human health.

In this study, we aimed to understand the involvement of animal- and human-derived fecal pollution sources in shaping integron prevalence and diversity in beach waters. Sampling was performed in the World Biosphere Reserve of Berlenga Island, located in the Atlantic Ocean, because here the sources of fecal pollution are limited and well-identified, consisting of both animal- and human-derived origins. The Berlenga Island 
constitutes an important nesting area of sea birds, in particular the yellow-legged gulls (Larus [cachinnans] michahellis), which are, by far, the dominant local fauna and a major source of fecal pollution in the island (Araújo et al., 2014). This island is only circumstantially inhabited by tourists in the summer season, and human-derived wastewaters are discharged near the coastline of the island without prior treatment (Araújo et al., 2014).

To address our aims, we examined the prevalence and diversity of integrons in E. coli strains collected from beach waters, as well as from seagull feces and raw wastewaters in the Berlenga Island. The association of integrons and plasmids was also assessed in order to determine the extent of the environmental risk at play.

\section{MATERIALS AND METHODS \\ SAMPLING, E. COLI ISOLATION AND MOLECULAR TYPING}

In a previous study, a collection of $939 \mathrm{E}$. coli isolates was obtained from samples collected between May and September 2011 at the Berlenga Island (Latitude: $39^{\circ} 24^{\prime} 52^{\prime \prime} \mathrm{N}$; Longitude: $9^{\circ} 30^{\prime} 22^{\prime \prime}$ W), located 5.7 miles northwest of Cape Carvoeiro, Portugal. Samples consisted of: (i) beach waters; (ii) composite seagull (Larus [cachinnans] michahellis) fresh fecal samples; and (iii) human-derived raw wastewaters (Araújo et al., 2014). Isolates were selected in Chromocult Coliform Agar, confirmed by plating in MacConkey and mFC agar and 16S rRNA gene sequencing, as previously described (Araújo et al., 2014). Molecular typing was performed by BOX-PCR (Araújo et al., 2014), resulting in a total of 414 different $E$. coli strains that were used in this study.

\section{INTEGRON SCREENING DETECTION AND CHARACTERIZATION}

E. coli strains were screened by PCR for the presence of class 1 and class 2 integrase genes (intI1 and intI2, respectively), as previously described (Moura et al., 2012b). Integrase-positive (intI ${ }^{+}$)-strains were further characterized. Class 1 and class 2 integron variable regions were amplified using primers targeting flanking regions of gene cassette arrays (class 1: intI1 or attI1 at $5^{\prime}$ region and tniC, qacE/sul1, or sul3 at $3^{\prime}$ region; class 2: intI2 or attI2 at $5^{\prime}$ region and $y b e A$ at $3^{\prime}$ region), using the Extensor Long Range PCR Master Mix (Thermo Scientific, USA), as described before (Moura et al., 2012b). Specific primers for gene cassettes were also used in primer walking. All primer sequences are listed in Table 1. Sequences obtained were subjected to BLAST (Altschul et al., 1997) searches against the INTEGRALL database (http:// integrall.bio.ua.pt; Moura et al., 2009). Insertion sequences were compared against ISFinder database (http://www-is.biotoul.fr; Siguier et al., 2006) to confirm identity. Gene cassette promoters were annotated according to Jové et al. (2010).

\section{PHYLOGROUPING AND ANTIBIOTIC SUSCEPTIBILITY PROFILES}

E. coli phylogenetic groups (A0, A1, B1, B2, D1, D2) were determined by PCR using the NZYTaq Green Master Mix (NZYTech, Portugal) and primers and conditions described before (Clermont et al., 2000; Figueira et al., 2011). Antibiotic susceptibilities were tested by disc diffusion agar according to the Clinical and Laboratory Standards Institute recommendations (CLSI, 2012) and using E. coli ATCC 25922 as control strain. The following antibiotics were tested: ampicillin (AMP, $10 \mu \mathrm{g})$, amoxicillin (AML, $10 \mu \mathrm{g}$ ), amoxicillin + clavulanic acid (AMC, $30 \mu \mathrm{g}$ ), piperacillin (PRL, $100 \mu \mathrm{g})$, piperacillin + tazobactam (TZP, $110 \mu \mathrm{g}$ ), cefalothin (CEF, $30 \mu \mathrm{g}$ ), ceftazidime (CAZ, $30 \mu \mathrm{g})$, cefotaxime (CTX, $30 \mu \mathrm{g})$, gentamicin (GEN, $10 \mu \mathrm{g})$, streptomycin (STR, $10 \mu \mathrm{g}$ ), imipenem (IPM, $10 \mu \mathrm{g}$ ), nalidixic acid (NAL, $30 \mu \mathrm{g}$ ), ciprofloxacin (CIP, $5 \mu \mathrm{g}$ ), tetracycline (TET, $30 \mu \mathrm{g}$ ), chloramphenicol (CHL, $30 \mu \mathrm{g})$ and trimethoprim/sulfamethoxazole (STX, $25 \mu \mathrm{g}$ ) (Oxoid, Basingstoke, UK).

\section{GENOMIC LOCATION OF INTEGRONS AND PLASMID CHARACTERIZATION}

To determine the genomic location (plasmid/chromosomal) of integrons, genomic DNA and plasmid DNA were extracted and purified using the Silica Bead DNA Extraction Kit (Thermo Scientific, USA) and the E.Z.N.A. Plasmid Mini Kit II (Omega Bio-tek, GA, USA), respectively. Aliquots were loaded onto $0.9 \%$ agarose gels and separated by electrophoresis at $80 \mathrm{~V}$ for $80 \mathrm{~min}$. Gels were then stained with ethidium bromide and documented with the Molecular Imager ${ }^{\circledR}$ Gel Doc $^{\mathrm{TM}}$ XR System and Image Lab $^{\text {TM }}$ Software (Bio-Rad, Hercules, CA, USA). DNA was transferred under vacuum onto positively charged nylon membranes (Hybond N+; Amersham, Freiburg, Germany) and subsequently cross-linked under UV irradiation for $5 \mathrm{~min}$. Hybridizations with intI1- and intI2-digoxigenin (DIG) labeled probes (Moura et al., 2007, 2012b) were performed overnight in 50\% formamide hybridization buffer at $42^{\circ} \mathrm{C}$. Detections were carried out using the DIG Nucleic Acid Detection Kit (Roche Diagnostics, Germany) following instructions provided by the manufacturer. Positive and negative controls were included in all experiments to confirm the specificity of detection.

In addition, int $I^{+}$-strains were included as donors in mating assays using rifampicin-resistant E. coli CV601-GFP (Smalla et al., 2006) as recipient strain, using previously described procedures (Moura et al., 2012a). Briefly, liquid cultures of donor and recipient strains were prepared separately in $10 \mathrm{~mL}$ LuriaBertani broth (LB) without antibiotics and grown overnight with gentle shaking at $28^{\circ} \mathrm{C}$. Recipient and donor strains were mixed (ratio 1:1) and centrifuged for $5 \mathrm{~min}$ at $6700 \mathrm{~g}$ to precipitate cells. Supernatants were discarded and replaced by $1 \mathrm{~mL}$ fresh LB. Mixtures were incubated overnight at $28^{\circ} \mathrm{C}$ without shaking. Cells were then precipitated by centrifugation for $5 \mathrm{~min}$ at $6700 \mathrm{~g}$ and washed in $0.9 \% \mathrm{NaCl}$ solution. Serial dilutions were prepared in $0.9 \% \mathrm{NaCl}$ and aliquots of $100 \mu \mathrm{L}$ were spread on Plate Count Agar plates supplemented with rifampicin (50 mg. $\left.\mathrm{L}^{-1}\right)$ and streptomycin $\left(50 \mathrm{mg} . \mathrm{L}^{-1}\right)$. Putative transconjugants were grown at $28^{\circ} \mathrm{C}$ for $48 \mathrm{~h}$. Assays were run in duplicate. Donor and recipient were also placed on the selective plates for mutant detection. Putative transconjugants growing in plates were confirmed by BOX-PCR typing by comparison with donor and recipient banding profiles. BOX-PCR reaction mixtures of $25 \mu \mathrm{L}$ consisted of $0.5 \times$ NZYTaq Green Master Mix (NZYtech, Portugal), $0.8 \mu \mathrm{M}$ of primer BOXAIR (5'-CTACGGCAAGGCGACGCTGACG-3'; Versalovic et al., 1991) and $1 \mu \mathrm{L}$ of cell suspension prepared in $100 \mu \mathrm{L}$ of distilled water $(\sim 1.0 \mathrm{McF}$ arland turbidity standard). Amplification was carried out as follows: initial denaturation for $7 \mathrm{~min}$ at $94^{\circ} \mathrm{C}$, then 30 cycles of denaturation at $94^{\circ} \mathrm{C}$ for $1 \mathrm{~min}$, followed by annealing at $53^{\circ} \mathrm{C}$ for $1 \mathrm{~min}$ and extension at $65^{\circ} \mathrm{C}$ for $8 \mathrm{~min}$, and a final extension at $65^{\circ} \mathrm{C}$ for $16 \mathrm{~min}$. Generated profiles 
Table 1 | Primers used in this study in the characterization of integrons.

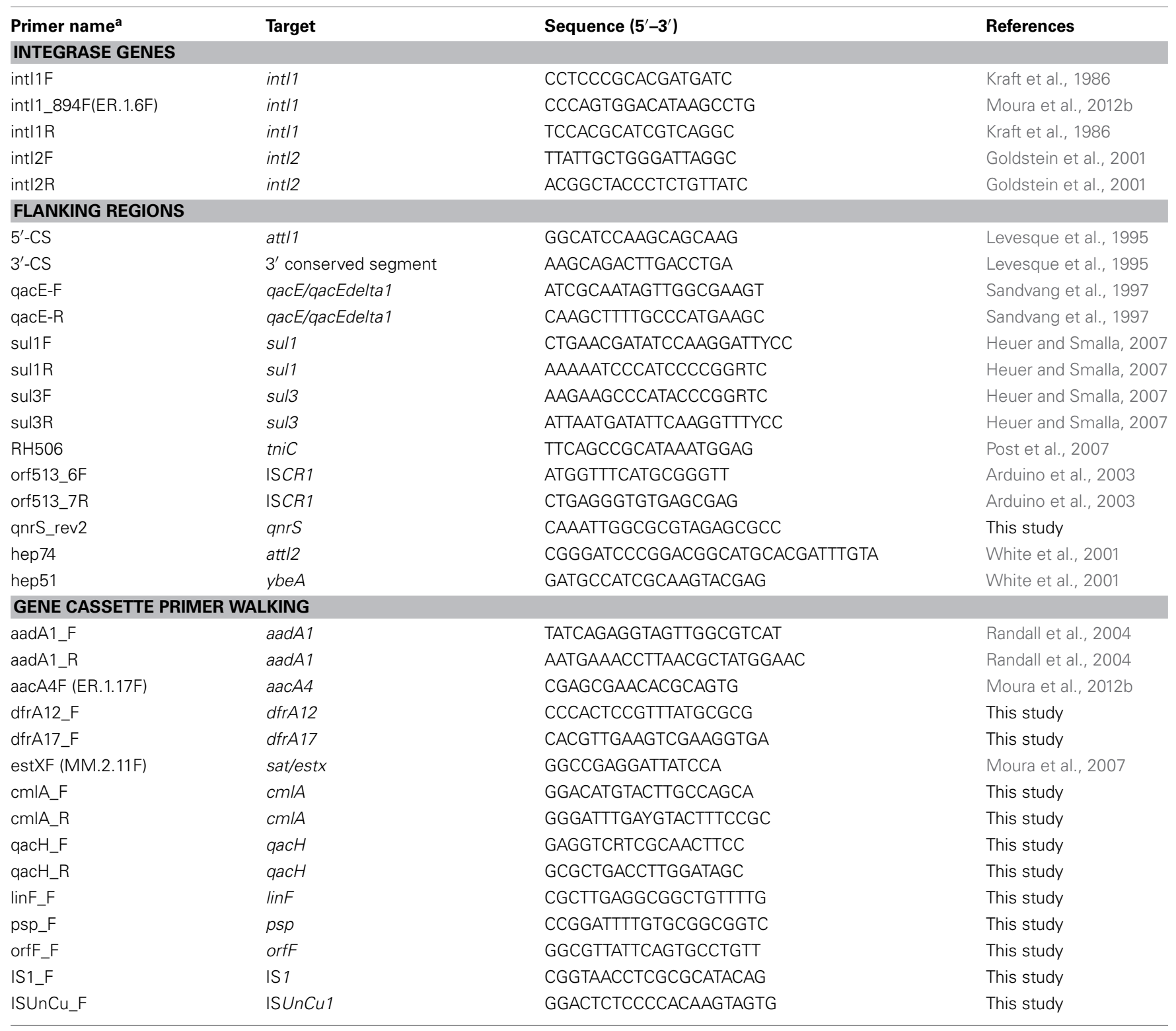

${ }^{a} F$, forward; $R$, reverse.

were separated in $1.5 \%$ agarose gels in TAE buffer $5 \times(50 \mathrm{mM}$ Tris, $50 \mathrm{mM}$ boric acid, $0.5 \mathrm{mM}$ EDTA), at $50 \mathrm{~V}$ for $95 \mathrm{~min}$, and stained with ethidium bromide. Plasmid DNA from transconjugants were extracted using E.Z.N.A. Plasmid Mini Kit II (Omega Bio-Tek, Georgia, USA), according to the manufacturer's instructions. Among transconjugants, diversity of plasmids was evaluated by PstI/Bst1770I restriction analyses and replicon typing, as previously described (Carattoli et al., 2005; Moura et al., 2012a). The antibiotic susceptibilities patterns of transconjugants were determined by the disc diffusion method as described above.

\section{STATISTICAL ANALYSES}

Pearson Chi-squared test $\left(\chi^{2}\right)$ was used to test the statistical significance $(P)$ of the distribution of integrons and replicons in the different sample sources. Associations were considered significant when $P$ was $<0.05$.

\section{NUCLEOTIDE SEOUENCE ACCESSION NUMBERS}

All integron sequences determined in this study were deposited in GenBank under the accession numbers KF921520 to KF921601.

\section{RESULTS AND DISCUSSION}

In this study, we investigated the occurrence of integrons and associated plasmids in $E$. coli strains $(N=414)$ from the World Biosphere Reserve of the Berlenga Island. Our goal was to understand whether the source of pollution, i.e., seagull feces (SF) and human-derived wastewaters (WW), influenced integron prevalence and diversity in E. coli from beach waters (BW). 

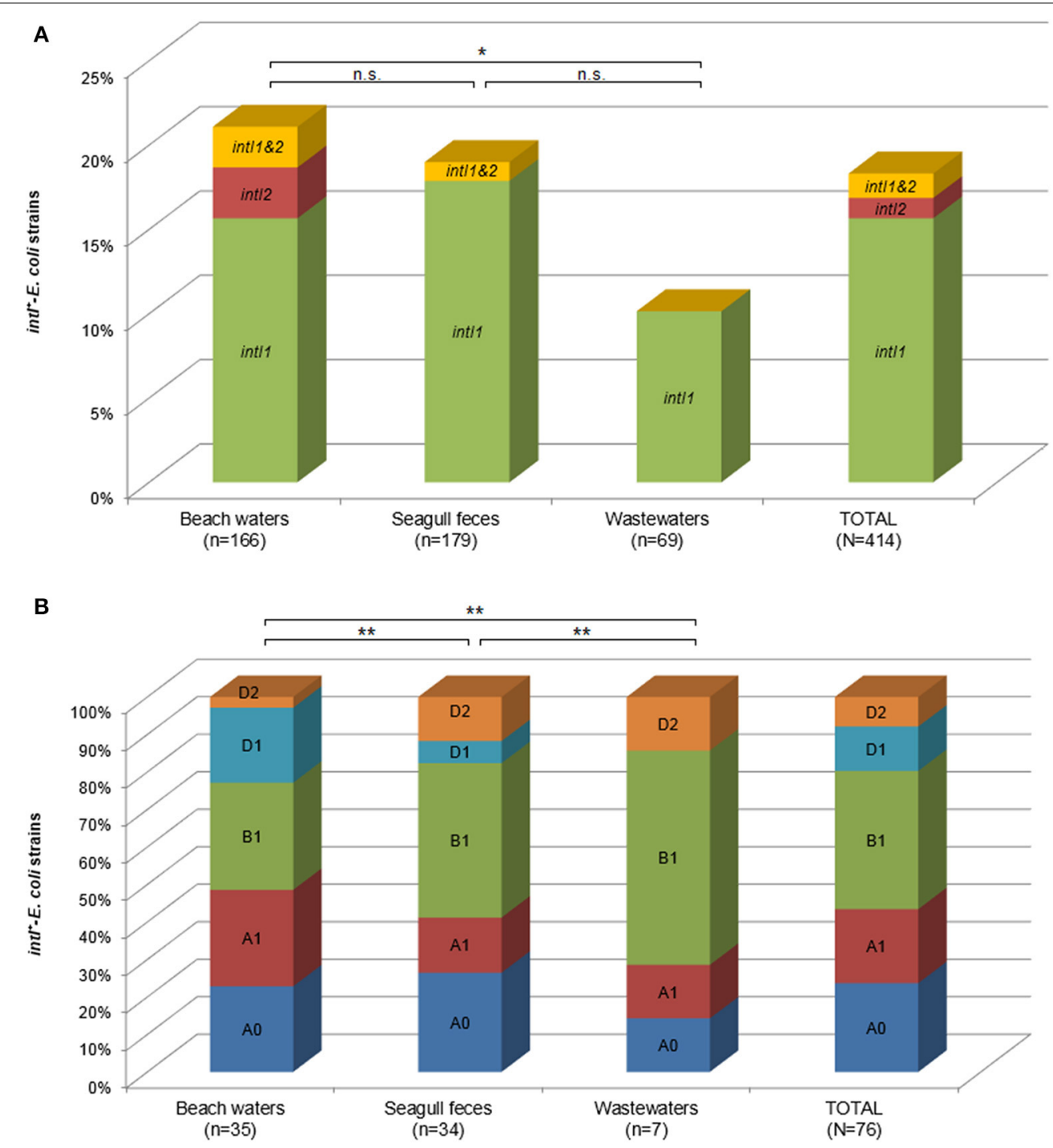

FIGURE 1 | Prevalence of int $^{+}{ }^{-}$-E. coli detected in the Berlenga Island among different sources (A) and phylogroups (B). Statistical significance: ${ }^{*} P<0.05 ;{ }^{* *} P<0.01$; n.s., not significant.

Overall, nearly $20 \%$ (76/414) of strains harbored intI genes (Figure 1A). Prevalence of class 1 and class 2 integron integrases was 18 and $2 \%$ in BW, 19 and $0.5 \%$ in SF and 10 and $0 \%$ in WW, respectively. Previous studies targeting antibiotic resistant bacteria in similar environments (Dolejska et al., 2009) have reported comparable prevalence of class 1 integrons in E. coli from surface waters $(21 \%)$ and black-headed gulls (Larus ridibundus) nesting nearby (15\%), although with higher prevalence of intI2 in gulls $(11 \%)$. Prevalence found at the untreated effluent of Berlengas was also similar to those found in raw human- and animalderived wastewaters (Moura et al., 2007, 2012b). In this study, differences between prevalence of intI genes in BW and WW were statistically different $\left(\chi_{1}^{2}=3.98 ; P<0.05\right)$, but not between BW and SF $\left(\chi_{1}^{2}=0.261 ; P>0.05\right)$. These results confirm the significant contribution of seagull microbiota in shaping the prevalence of integrons in this ecosystem.
Phylotyping showed a wide intraspecific diversity among integron carrying $\left(\right.$ int I $\left.^{+}\right)$-E. coli. As shown in Figure 1B, the majority of intI $^{+}$-strains affiliated to commensal phylogroups B1 (37\%), A0 (24\%), and A1 (20\%). The prevalence of intI genes among phylogroups was not statistically significant $\left(\chi_{5}^{2}=\right.$ 4.70; $P>0.05$ ), being more constraint by the association of the different $E$. coli phylogroups to the different ecological niches (Figure 1B).

Table 2 provides the detailed characterization of the 76 intI ${ }^{+}$E. coli strains obtained in this study. Up to 18 different gene cassettes were found organized into 18 distinct arrays (summarized in Table 3). Common arrays were found among strains from different sources. Gene cassettes detected coded for resistance to aminoglycosides (aadA1, $\triangle$ aadA1, aadA2, aadA5, aadB, aacA4, sat2), trimethoprim (dfrA1, dfrA12, dfrA14, dfrA17), chloramphenicol (cmlA1, catB3), lincosamides (linF) and quaternary 


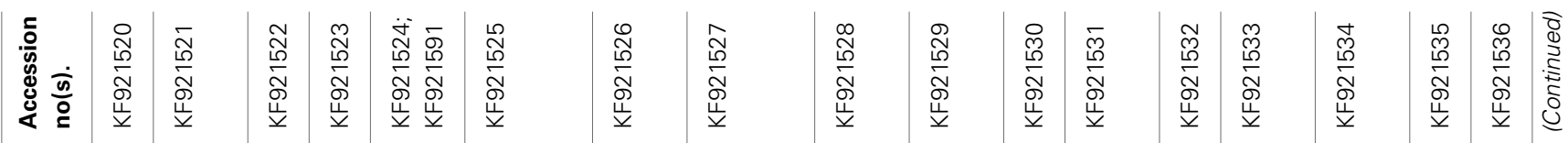

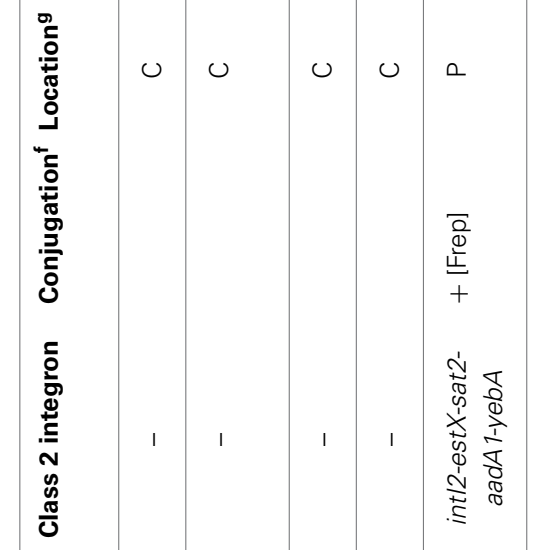

ะ

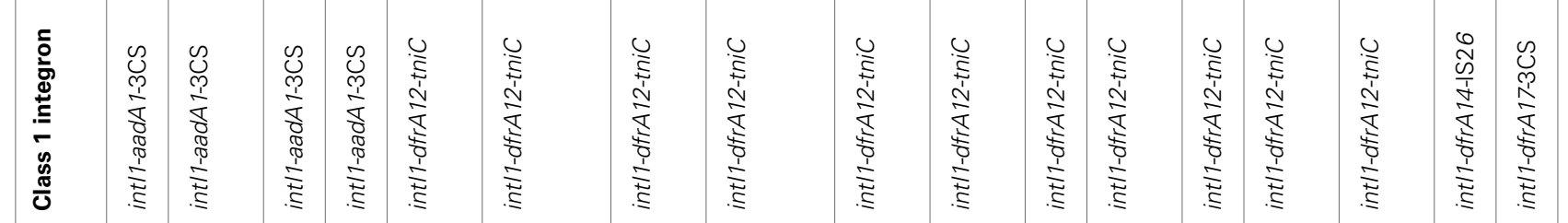

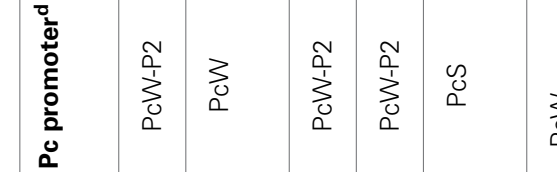
.
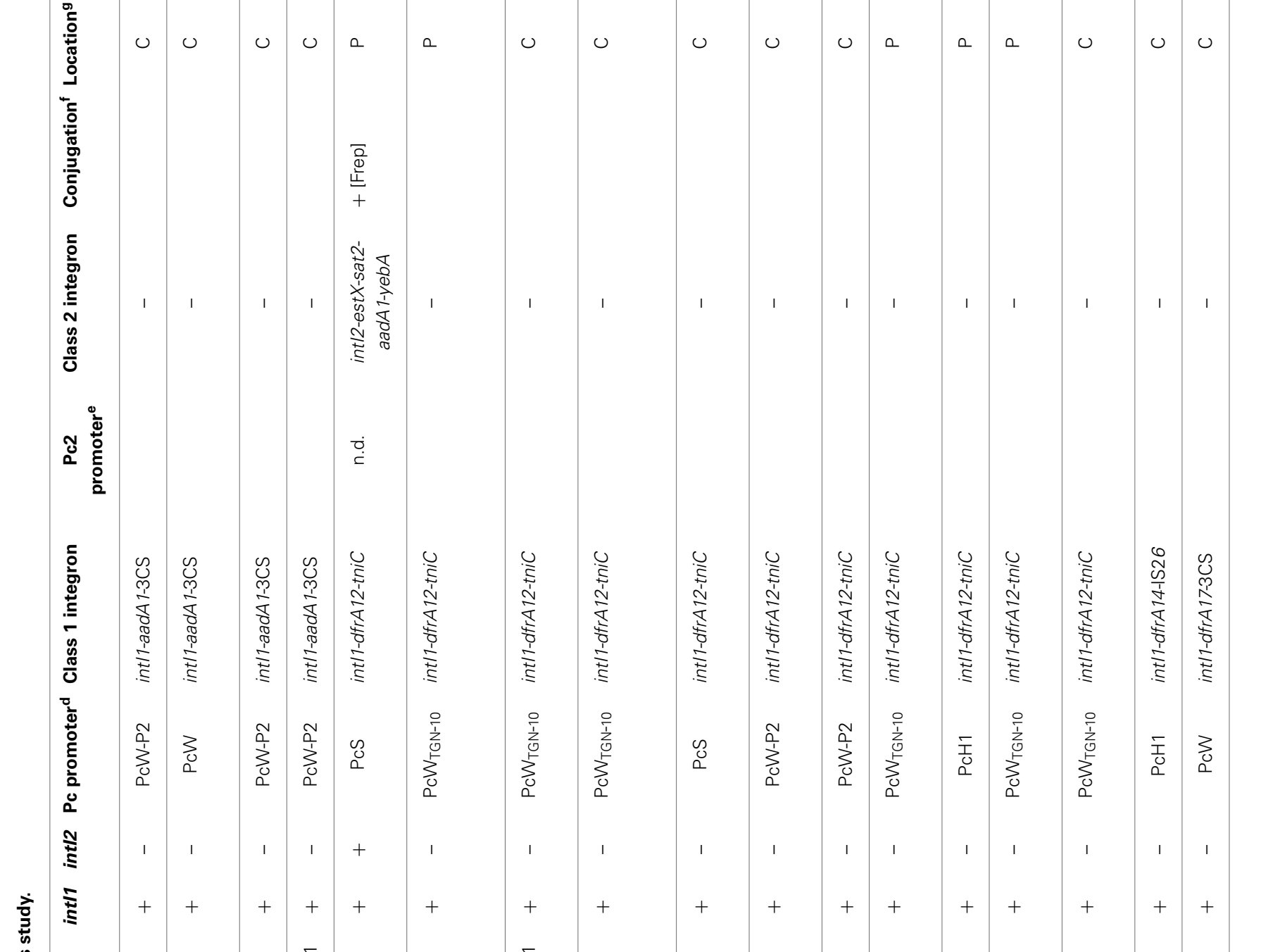

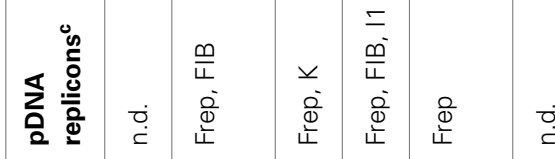

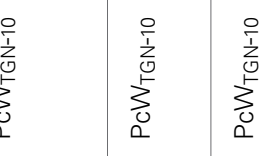

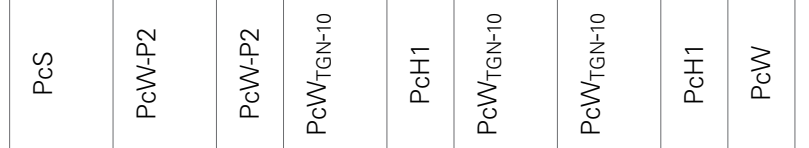

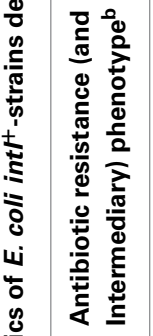

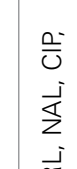

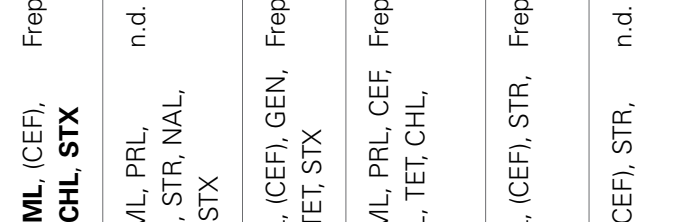

$\frac{1}{\sqrt[3]{3}}$

(1)

.

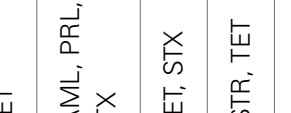

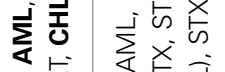

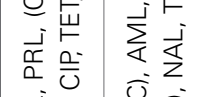

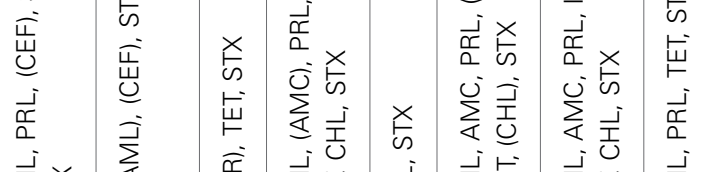

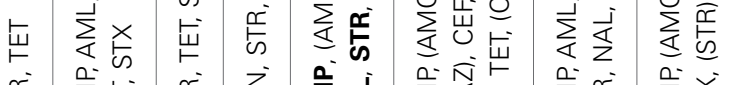

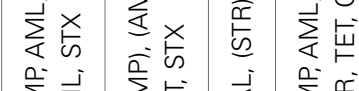

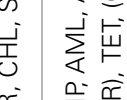

采它亲希

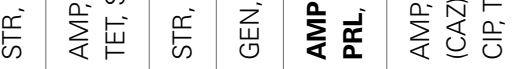

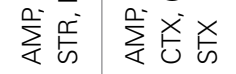

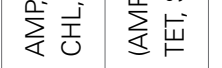

$\bar{\square} \bar{\infty}$

ธิ ป

운

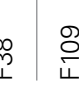

ㅇํำ

㚣

₹ 8

$\overline{4}$

8

운

$\bar{\infty} \bar{\infty}$

$\bar{\varnothing} \bar{\infty} \bar{\infty}$

曼

受

尊要 


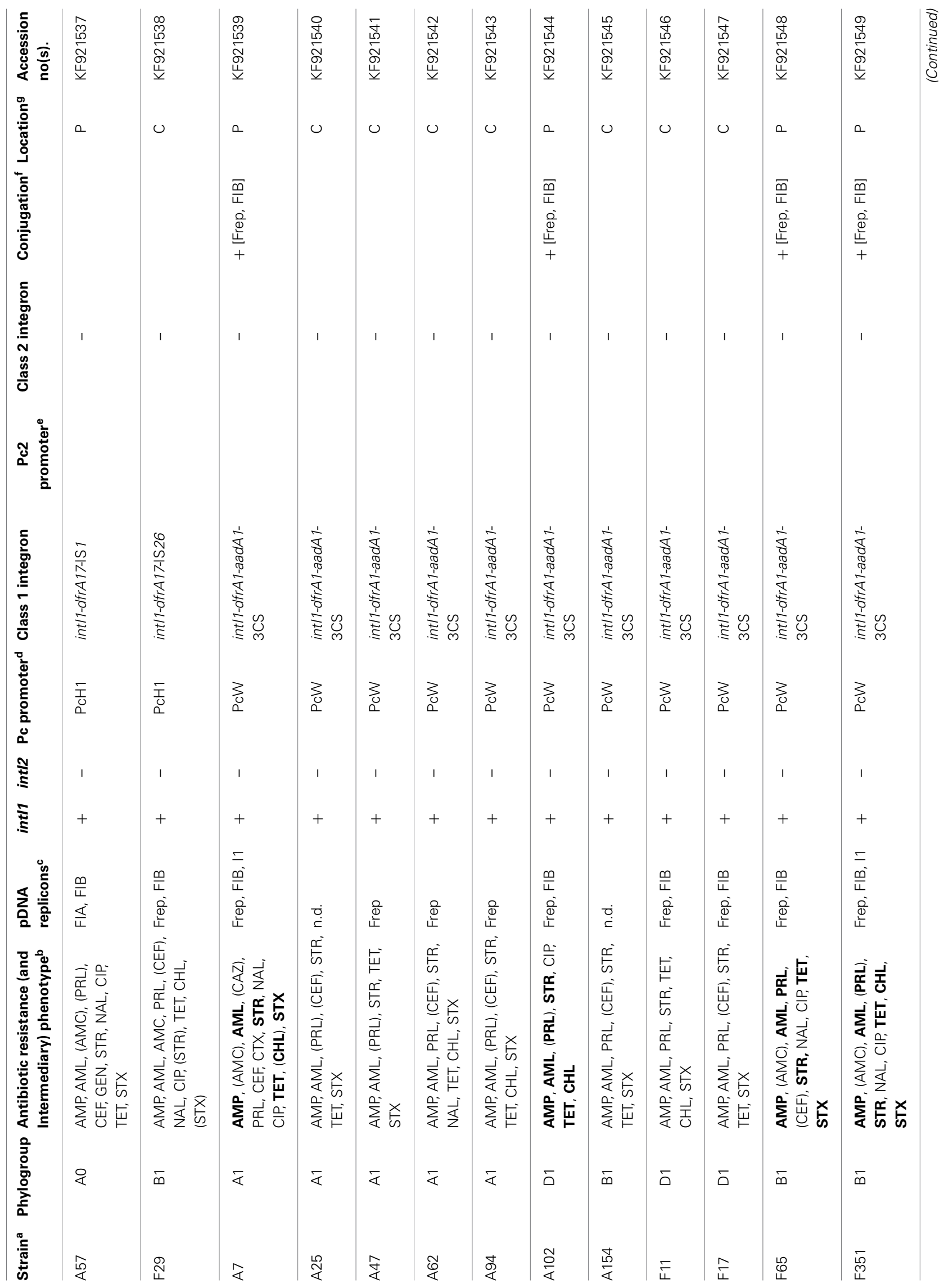




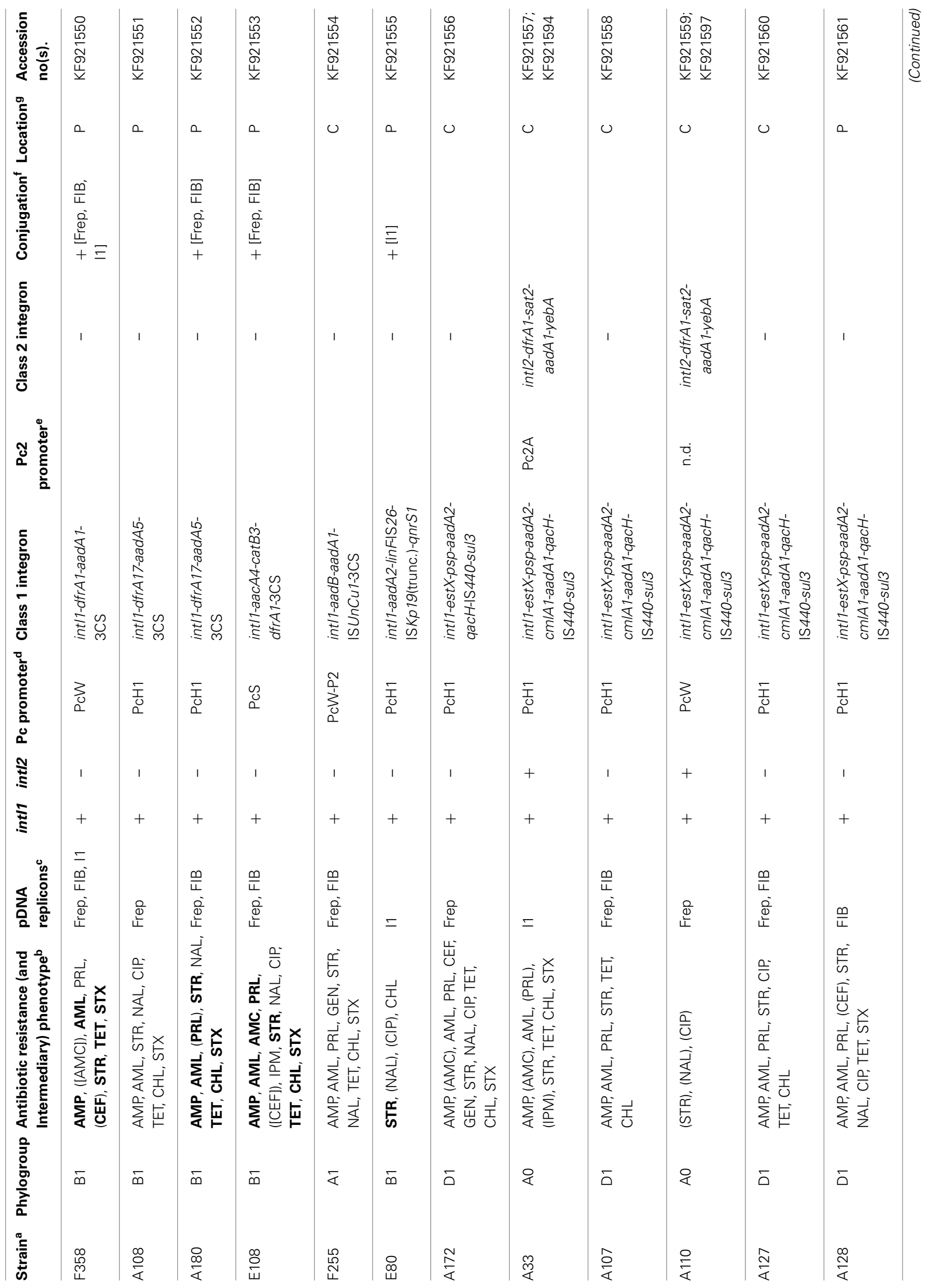




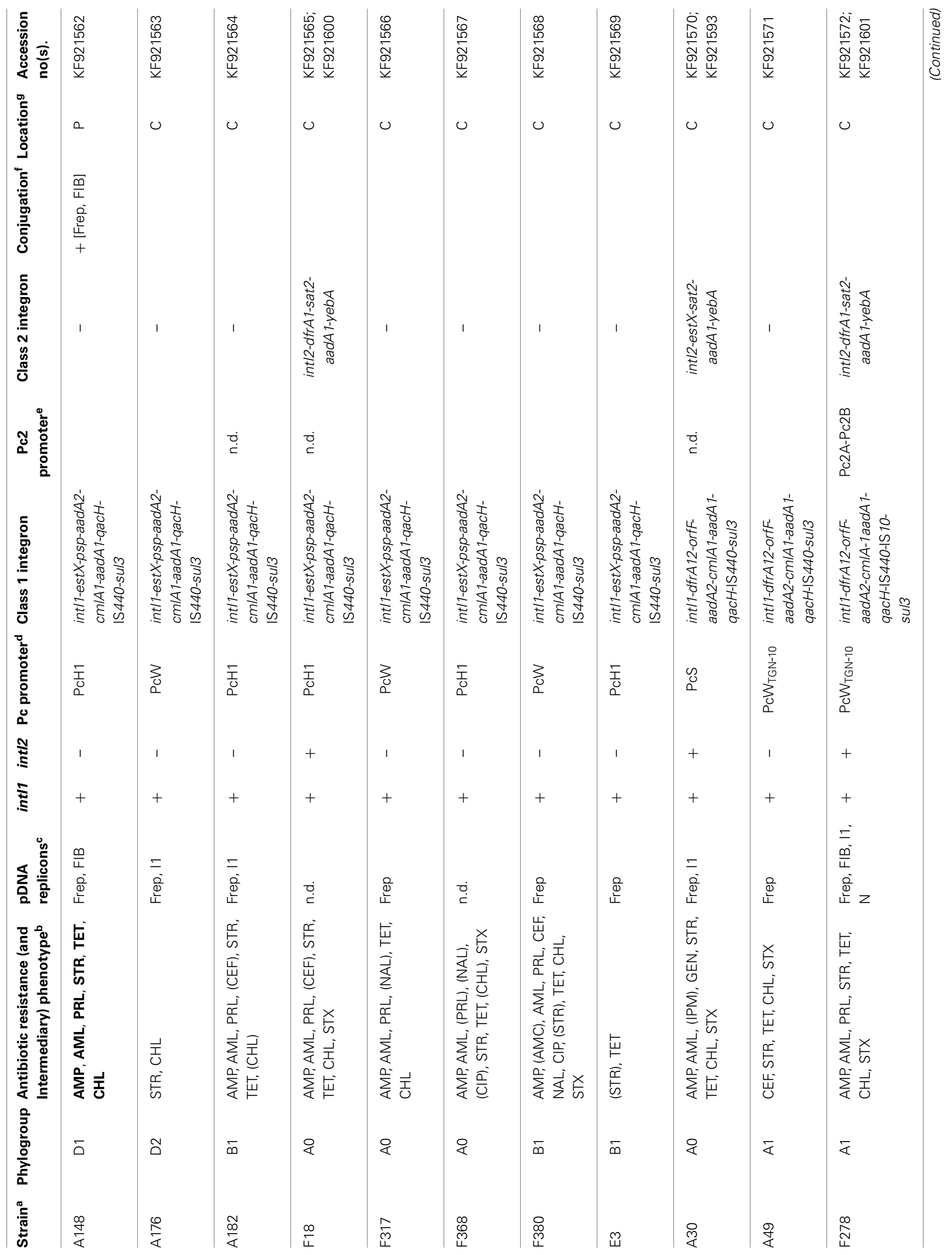




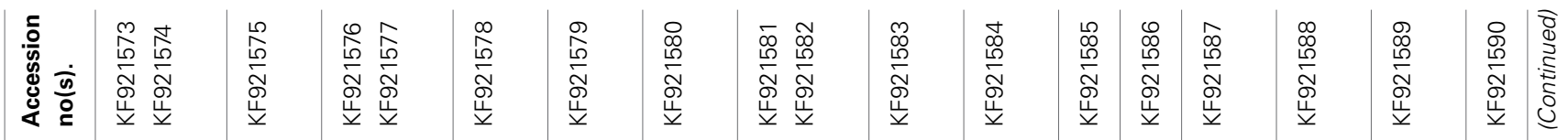

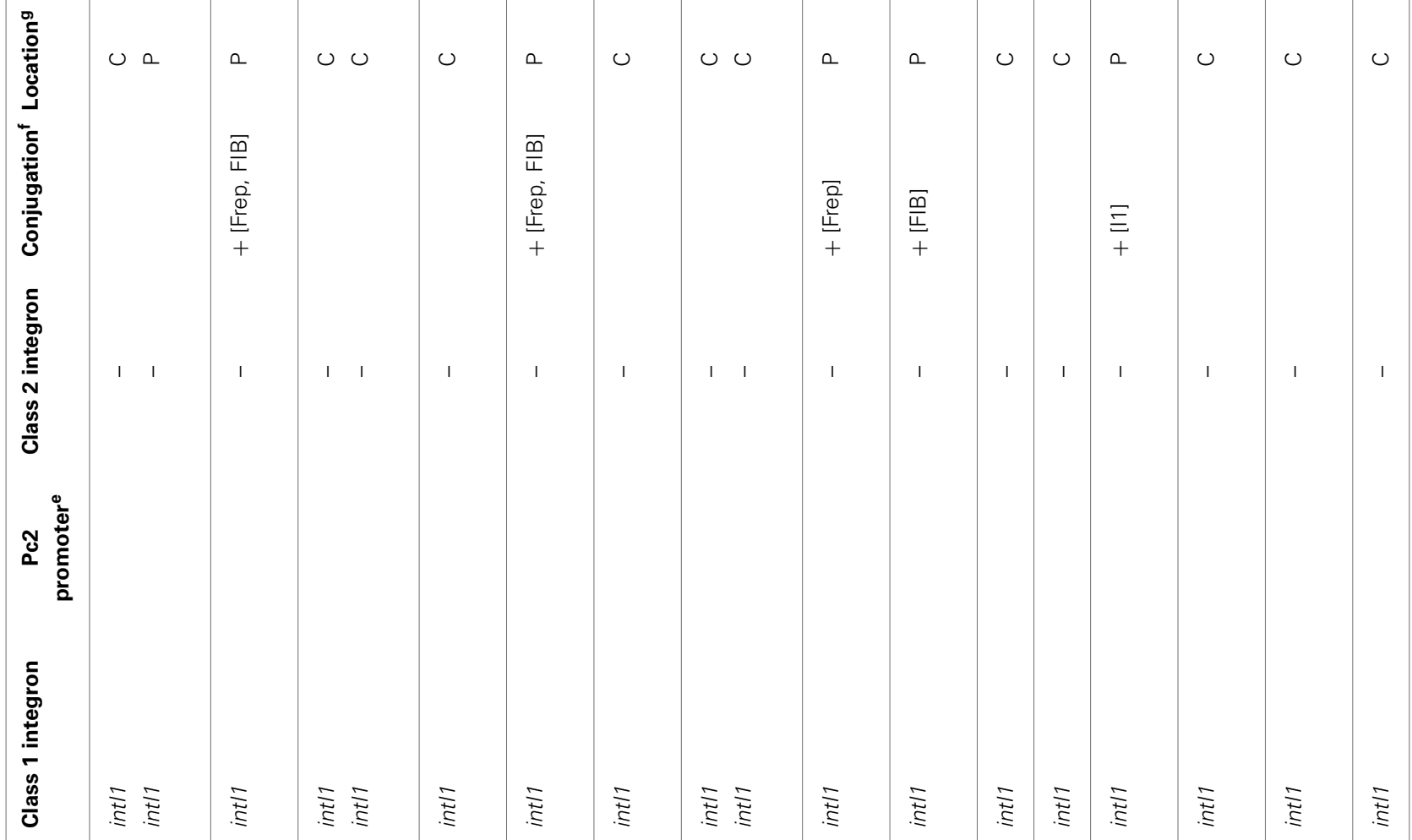

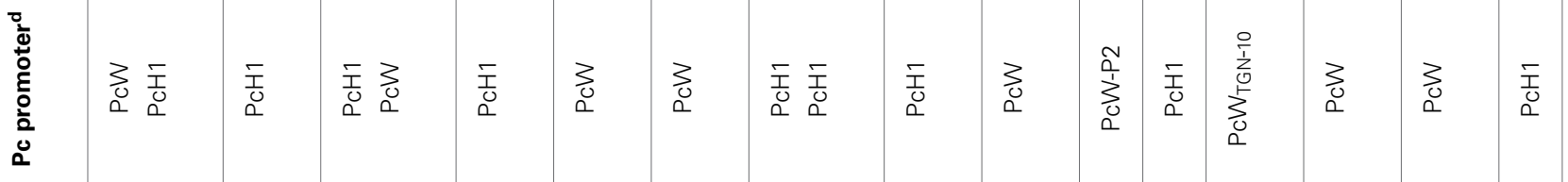

\begin{tabular}{|c|c|c|}
\hline 11 & 1 & 11 \\
\hline++ & + & ++ \\
\hline
\end{tabular}

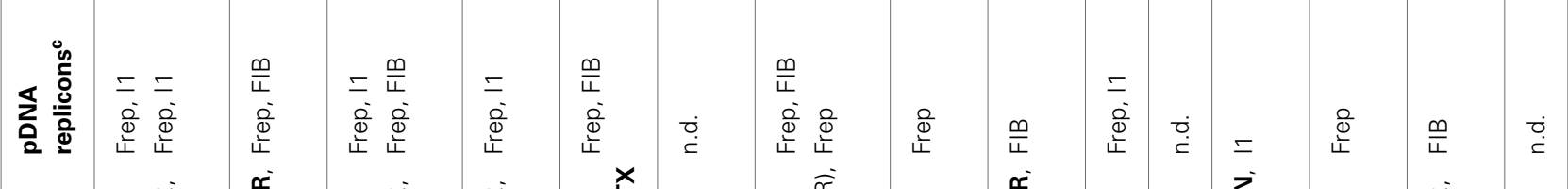

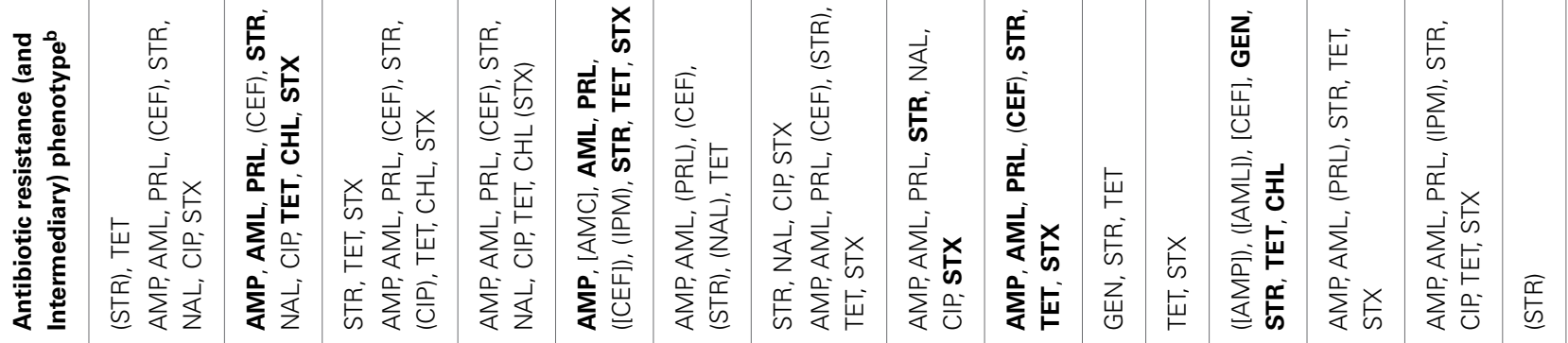

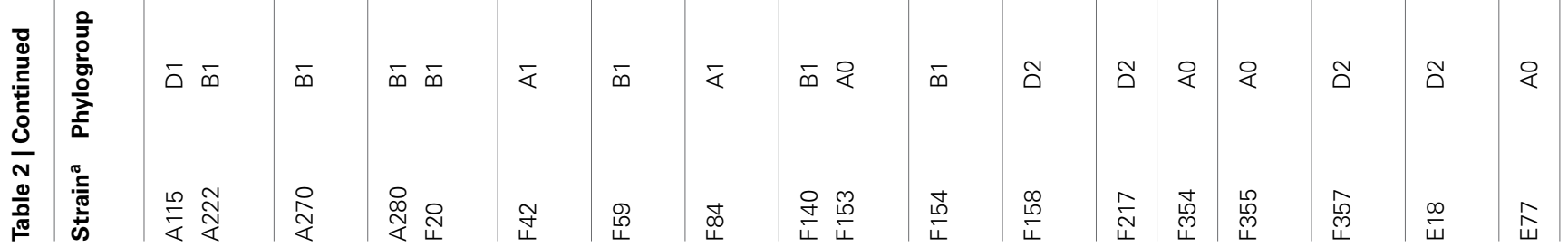




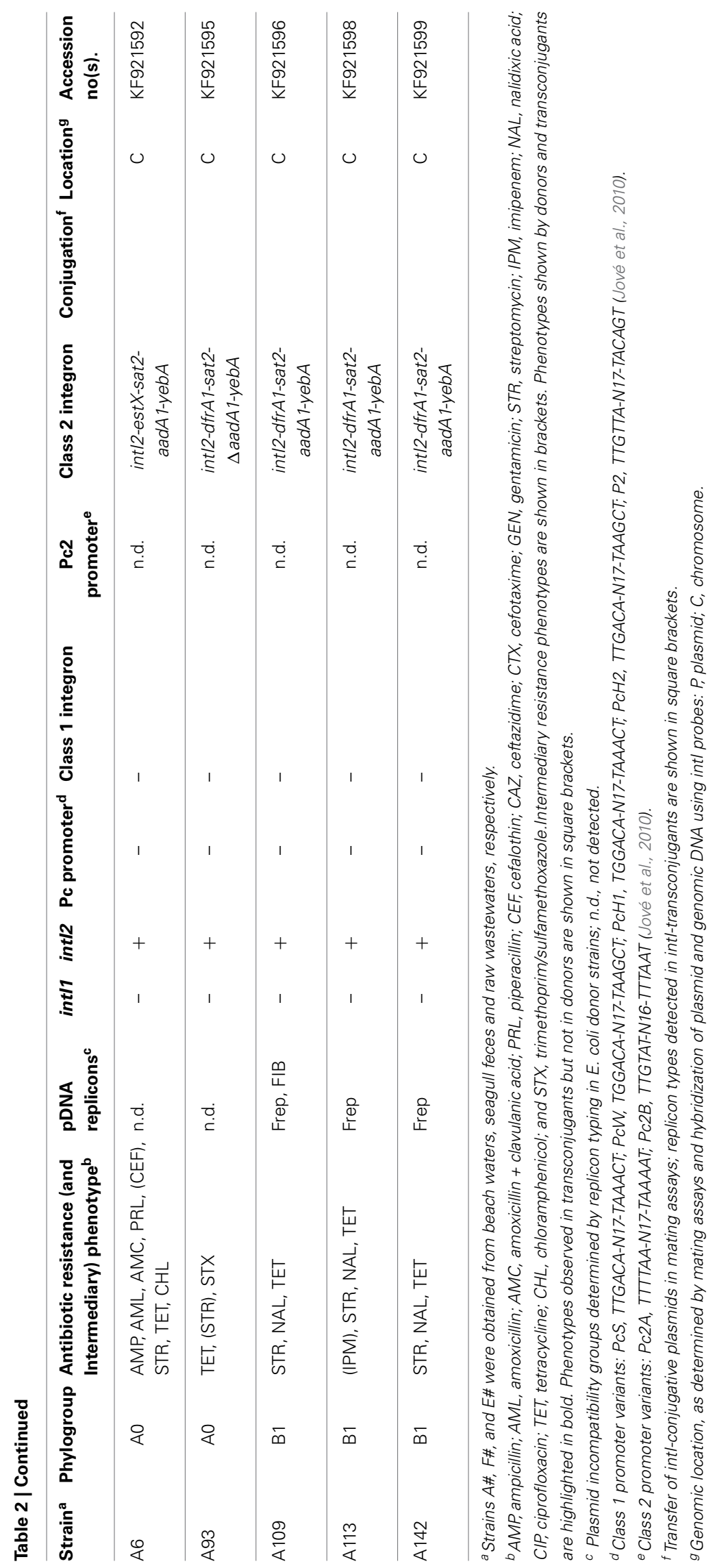


Table 3 | Overview of the gene cassette arrays and Pc promoter variants present in the 82 integron structures detected in this study among intl $^{+}$-E. coli strains isolated from beach waters (BW), seagull feces (SF) and wastewaters (WW).

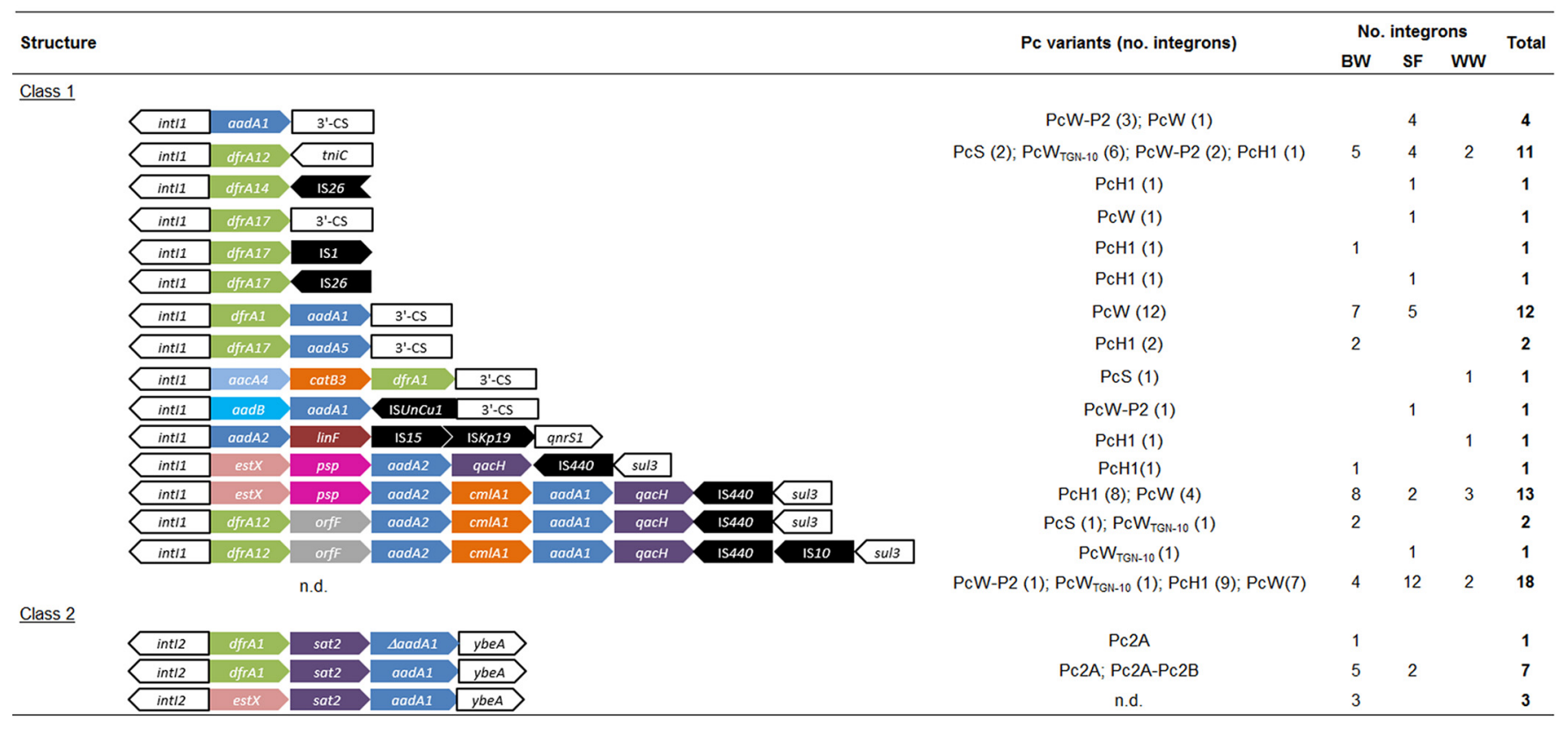

ammonia compounds ( $q a c H)$. In addition, gene cassettes coding for putative esterases (est $X$ ) and phosphoserine phosphatases $(p s p)$, as well gene cassettes of unknown function (orf $F$ ) were also present. Though not as part of gene cassettes, genes coding for quinolone resistance ( $q n r S 1$ ), quaternary ammonia compounds (qacEdelta1) and sulfonamides (sul1, sul3) were also associated with the integrons found.

Thus, integron structures detected contained genes involved in diverse resistance mechanisms, including enzymatic antibiotic modification ( $a a d A, a a d B, a a c A, c a t B$, sat, sul), efflux pumps $(q a c H, q a c E)$ and target protection proteins ( $q n r S)$. This diversity of resistance mechanisms largely contributed to the high prevalence of multiresistant $i n t I^{+}-E$. coli $(64 / 76,83 \%$; considering simultaneous resistance to 3 or more different classes of antibiotics), although the presence of additional mechanisms of resistance besides those within integrons cannot be excluded. Prevalence of multi-resistant strains in BW (89\%) was statistically different from that observed in WW (57\%), but not to the one observed in SF (82\%). Overall, the most frequently resistances detected were against tetracycline $(87 \%)$, streptomycin (79\%), ampicillin (70\%), amoxicillin (70\%), trimethoprimsulfamethoxazole (70\%), piperacillin (53\%), and chloramphenicol (45\%) (Figure 2). Differences among sources were not statistically significant, except for resistances against amoxicillin+clavulanic acid and imipenem, that were more prevalent in wastewaters $(P<0.01)$. The prevalence and risk of dissemination of resistant strains to last-resort antibiotics, such as imipenem, is nowadays a matter of great concern, reducing treatment options for infectious diseases. Imipenem resistance if often associated to the presence of integron-borne carbapenemase gene cassetes, such as $b l a_{\mathrm{VIM}}, b l a_{\mathrm{IMP}}$, and $b l a_{\mathrm{GES}}$ (INTEGRALL database, Moura et al., 2009) and/or plasmid-borne carbapenemases, such as $b l a_{\mathrm{KPC}}, b l a_{\mathrm{OXA}-48}$, and $b l a_{\mathrm{NDM}-1}$ (Carattoli, 2013). Nevertheless, none of these mechanisms have been detected in these strains (Alves et al., 2014). Further investigations will allow to elucidate the mechanisms of carbapenem resistance present in these strains as well their potential risk of dissemination into natural environments.

Different insertion sequences (IS1, IS10, IS15, IS26, IS440, ISKp19, ISUnCu1) were also found within $50 \%(9 / 18)$ of the different arrays (Tables 2-3). Comparative analyses of 20 E. coli genomes have also shown the presence of a large number of ISlike elements, constituting $21 \%$ of all genes annotated (Touchon et al., 2009) and likely to contribute to the high genome dynamics and adaptation seen in E. coli.

Class 1 integrons lacking the $3^{\prime}$-conserved segment (qacEdelta1/sul1) represented nearly half of int $1 I^{+}-E$. coli strains $(33 / 71 ; 46.5 \%)$. These included sul3-type $(n=17)$ integrons and Tn402-derivative integrons containing tniC $(n=11)$. Dissemination of sul3-containing elements linked to class 1 integrons with an unusual $3^{\prime} \mathrm{CS}$ region has been reported among clinical and meat-associated Salmonella and E. coli isolates, including in poultry, often as large platforms with the structures intI1-dfrA12-orfF-aadA2-cmlA1-aadA1-qacH-IS440sul3 or intI1-estX-psp-aadA2-cmlA1-aadA1-qacH-IS440-sul3 (Antunes et al., 2007; Sáenz et al., 2010; Curiao et al., 2011; Pérez-Moreno et al., 2013), as observed in this study. Although some variations in these array structures may occur, such as additional IS insertions (e.g., IS10 in intI1-dfrA12-orfF-aadA2cmlA1-aadA1-qacH-IS440-IS10-sul3, Tables 2-3) or gene cassette deletions (e.g., cmlA1-aadA1 in the structure intI1-estX-pspaadA2-qacH-IS440-sul3, Tables 2-3), the apparent conservation and dissemination of these arrays among isolates from different sources and countries, suggest their mobilization through horizontal gene transfer or specific clone dissemination and diversification, rather than cumulative gene cassette acquisition. 


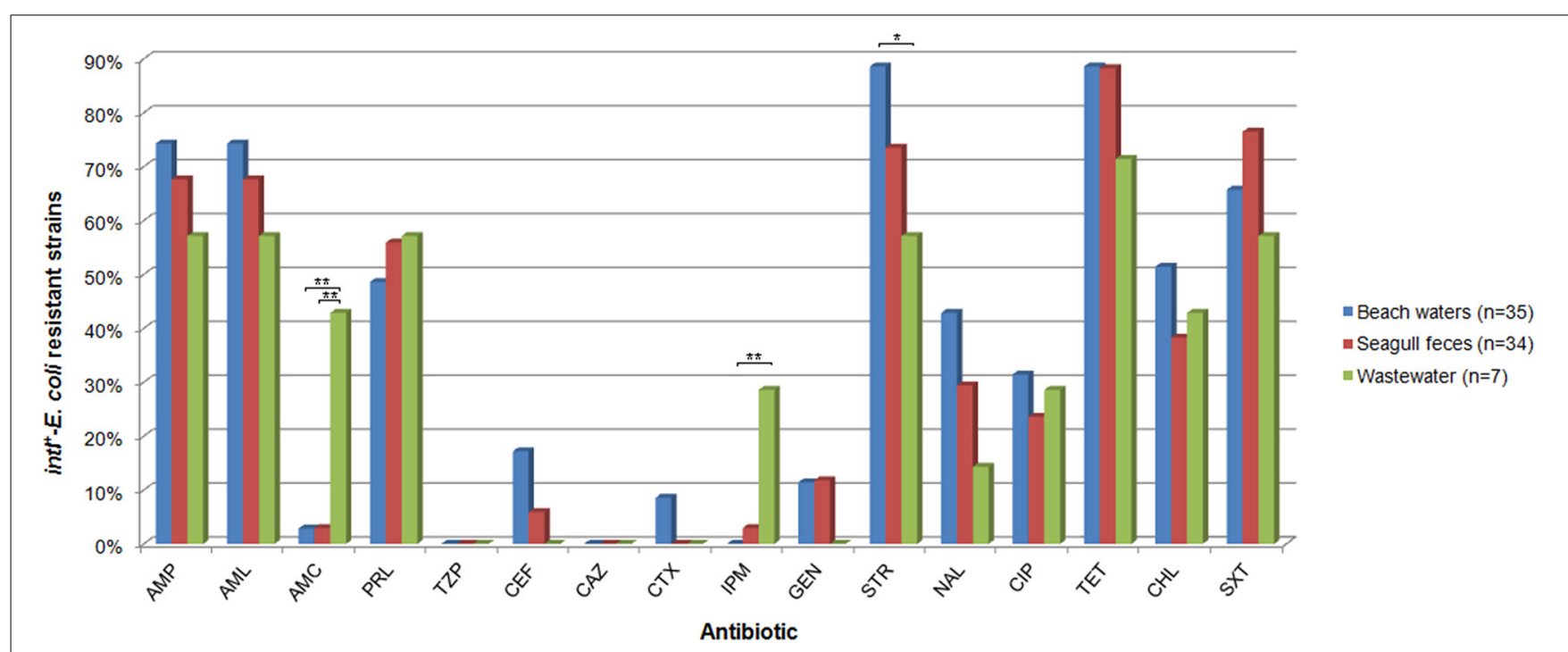

FIGURE 2 | Prevalence of antimicrobial resistance in int/ + $^{-}$. coli strains. Antibiotic abbreviations: AMP, ampicillin; $A M L$, amoxicillin; $A M C$, amoxicillin + clavulanic acid; $P R L$, piperacillin; TZP, piperacillin + tazobactam; CEF, cefalothin; CAZ, ceftazidime; CTX, cefotaxime; GEN, gentamicin; STR, streptomycin; IPM, imipenem; NAL, nalidixic acid; CIP, ciprofloxacin; TET, tetracycline; CHL, chloramphenicol; STX, trimethoprim/sulfamethoxazole. Only statistical significant differences are shown: ${ }^{*} P<0.05 ; * * P<0.01$.
Tn402-derivative integrons are thought to be the progenitors of classical class 1 integrons that contain the $3^{\prime}$-conserved segment (Post et al., 2007). Integrons derived from Tn402 are flanked by the $t n i C$ gene (also called $t n i R$ ) that makes part of the transposition $t n i A B Q C$ module. Reports of tniC-like integrons are scarce likely because gene cassette characterization usually relies only on the amplification of $3^{\prime}$-CS conservative region (Post et al., 2007). At INTEGRALL database, tniC-integrons have been identified in few Pseudomonas putida, Pseudomonas aeruginosa, Aeromonas caviae and IncP-1 plasmids, many of those containing gene cassettes coding resistance against beta-lactams ( bla $_{\mathrm{VIM}}$, $\left.b l a_{\mathrm{OXA}}, b l a_{\mathrm{NPS}-1}\right)$, aminoglycosides (aacA4, aacA7, aacC5, aadA1, aadA11) and trimetophrim (dfrB5). In this study, all tniCintegrons carried the dihydrofolate reductase $d f r A 12$ gene cassette, coding for resistance to trimethoprim, and it constitutes the first report on tniC-like integrons in E. coli.

No significant differences were found on promoter distribution accordingly to sample origin $\left(\chi_{10}^{2}=16.25 ; P>0.05\right)$, contrarily to what has been observed in animal- and human-derived wastewaters (Moura et al., 2012c). The majority of integrons detected possessed weak Pc promoter variants $(\mathrm{PcW}$ and $\mathrm{PcH}$ ), which are known to be associated to weak expression of gene cassette arrays (Jové et al., 2010). PcH1 and PcW variants were more prevalent among A0 and B1 phylogroups $\left(\chi_{20}^{2}=36.56 ; P<\right.$ $0.01)$. Previous studies concerning aquatic environments have also reported higher prevalence of weaker promoters among environmental strains (Moura et al., 2012c; Tacão et al., 2014), as well as studies concerning commensal microbiota (Soufi et al., 2009). Weaker Pc variants are associated to a higher capacity for gene cassette rearrangements, leading to more dynamic arrays (Jové et al., 2010). Interestingly, among tniC-type integrons stronger Pc variants were identified: PcS $(n=2), \mathrm{PcW}_{\mathrm{TGG}-10}(n=6), \mathrm{PcW}-$ $\mathrm{P} 2(n=1)$. These results corroborate that integron platforms had probably evolved to favor high rate of gene cassette recombination compensating low expression levels and contributing to genome plasticity, as discussed before (Moura et al., 2012c).

Similar to previous reports on plasmid diversity among intI $\mathrm{I}_{\text {- }}$ strains (Moura et al., 2012a), a wide and diverse plasmid pool was present in these E. coli (Figure 3A). Replicons were detected in $80 \%(60 / 76)$ of strains (Figure 3A; Table 2), though differences among BW, SF, and WW were not statistically significant. Replicons detected belonged to IncF (Frep, FIA, and FIB subgroups), IncI1, IncN, IncY, and IncK incompatibility groups. More than one replicon type was detected in $41 \%(31 / 76)$ of strains. In strains from phylogroups A0 and B1, up to 5 different replicon types were detected (Figure 3B). Integrons were successfully mobilized through IncF (Frep and FIB subgroups) and IncI1 conjugative plasmids into E. coli CV601 in 20\% $(15 / 76)$ of strains, using streptomycin as selective marker. The majority of intI-transconjugants displayed the resistance patterns observed in donor strains (Table 2), highlighting the importance of co-selection in the spread of multi-resistance traits through horizontal gene transfer. Plasmid DNA from transconjugants showed different restriction patterns (data not shown), including in transconjugants from donors that shared identical integron structures. These results may be explained by the presence of identical integron platforms in different plasmids. Nevertheless, the co-mobilization of multiple plasmids and/or the occurrence of genetic rearrangements in transconjugants resulting in different restriction patterns cannot be excluded. It is also noteworthy that plasmid prevalence and diversity, as well as their transfer ability may be, however, under-estimated due to biases introduced by the technical approaches. Alkaline extraction of plasmid DNA may affect the efficiency to recover larger plasmids, and the mating conditions used may favor the transfer the plasmids of IncF and IncI complexes, which are liquid maters. 


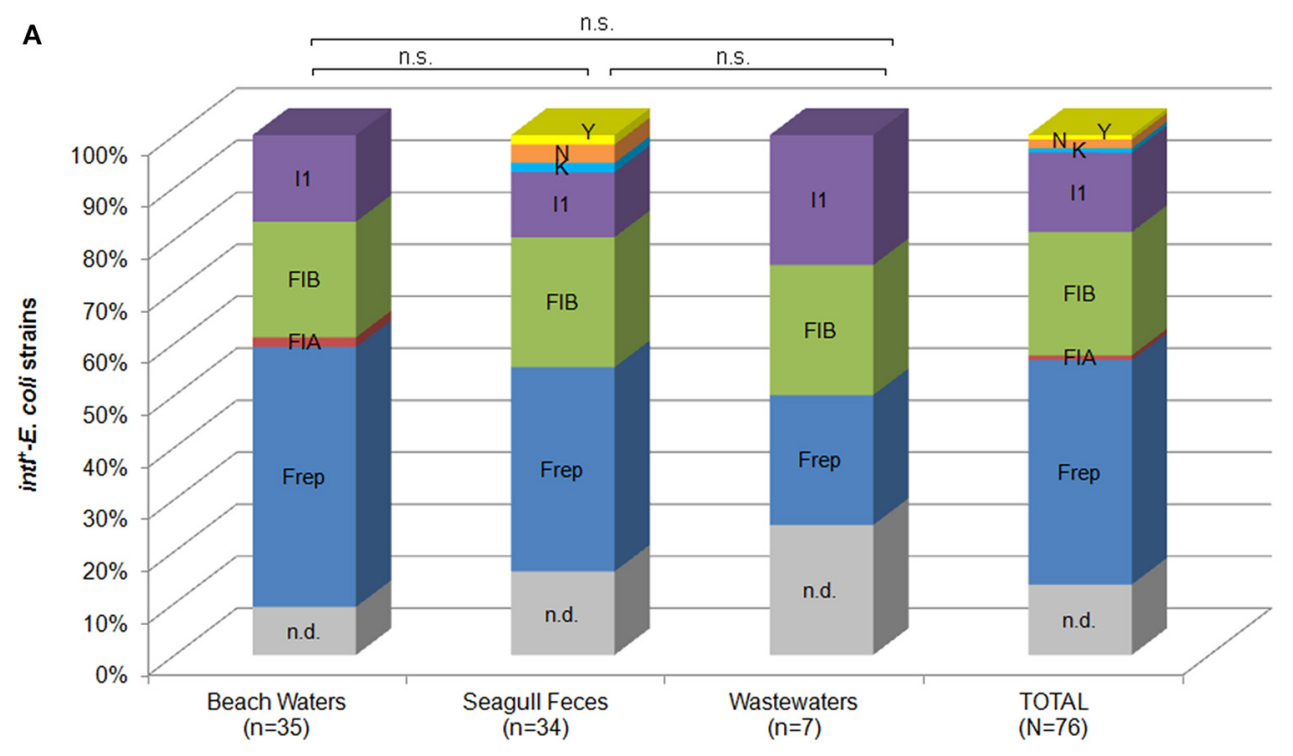

B

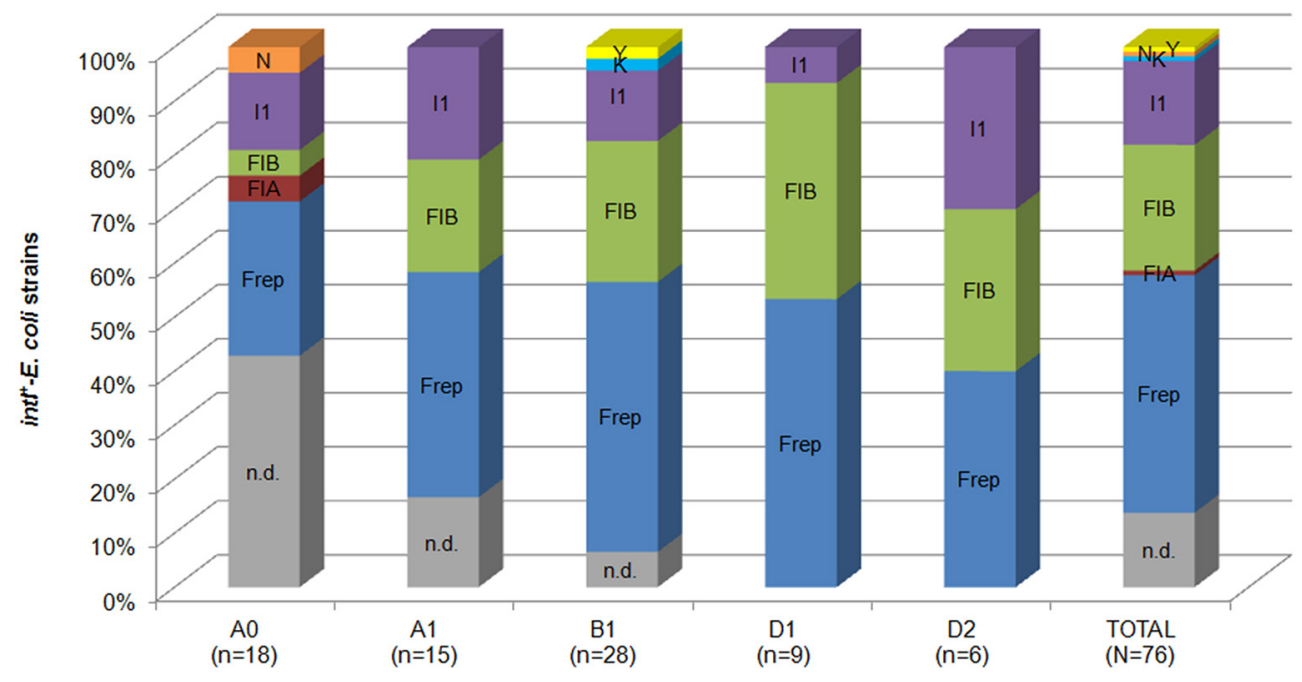

FIGURE 3 | Prevalence of replicon types detected in int/ ${ }^{+}-$E. coli among different sources (A) and phylogroups (B). Abbreviations: n.d., not detected; n.s., not statistically significant.

In conclusion, results obtained confirmed the existence of a diverse integron pool in this coastal environment, associated with different resistance traits and plasmid incompatibility groups. The prevalence and diversity of integrons, as well as of multidrug resistance phenotypes, found in beach waters were more influenced by animal-derived fecal inputs rather human-derived wastewaters. Results obtained thus reinforce the important input of commensal E. coli from wild animals in this ecosystem, largely dominated by seagulls. These findings underscore the role of wild life in dissemination of integrons and antibiotic resistance traits in natural environments.

\section{ACKNOWLEDGMENTS}

The authors wish to thank Alessandra Carattoli (Department of Infectious, Parasitic and Immune-Mediated Diseases, Istituto
Superiore di Sanità, Italy) for providing replicon typing control strains. This work was supported by European Funds through COMPETE and by National Funds through FCTFundação para a Ciência e a Tecnologia within the projects PEstC/MAR/LA0017/2013 and SEAGULL (FCOMP-01-0124-FEDER008640, PTDC/AAC-AMB/109155/2008). FCT also financed the grants SFRH/BPD/72256/2010 (Alexandra Moura) and SFRH/BPD/26685/2006 (Anabela Pereira). Isabel Henriques received an individual Research Assistant contract within the project Sustainable Use of Marine Resources MARES (CENTRO07-ST24-FEDER-002033), co-financed by QREN (Mais CentroPrograma Operacional Regional do Centro) and FEDER.

\section{REFERENCES}

Altschul, S. F., Madden, T. L., Schaffer, A. A., Zhang, J., Zhang, Z., Miller, W., et al. (1997). Gapped BLAST and PSI-BLAST: a new generation of protein database 
search programs. Nucleic Acids Res. 25, 3389-3402. doi: 10.1093/nar/25. 17.3389

Alves, M. S., Pereira, A., Araujo, S. M., Castro, B. B., Correia, A. C., and Henriques, I. (2014). Seawater is a reservoir of multi-resistant Escherichia coli, including strains hosting plasmid-mediated quinolones resistance and extendedspectrum beta-lactamases genes. Front. Microbiol. 5:426. doi: 10.3389/fmicb. 2014.00426

Andersson, D. I., and Hughes, D. (2011). Persistence of antibiotic resistance in bacterial populations. FEMS Microbiol. Rev. 35, 901-911. doi: 10.1111/j.15746976.2011.00289.x

Antunes, P., Machado, J., and Peixe, L. (2007). Dissemination of sul3containing elements linked to class 1 integrons with an unusual 3' conserved sequence region among Salmonella isolates. Antimicrob. Agents Chemother. 51, 1545-1548. doi: 10.1128/AAC.01275-06

Araújo, S., Henriques, I. S., Leando, S. M., Alves, A., Pereira, A., and Correia, A. (2014). Gulls identified as major source of fecal pollution in coastal waters: a microbial source tracking study. Sci. Total Environ. 470-471, 84-91. doi: 10.1016/j.scitotenv.2013.09.075

Arduino, S. M., Catalano, M., Orman, B. E., Roy, P. H., and Centron, D. (2003). Molecular epidemiology of orf513-bearing class 1 integrons in multiresistant clinical isolates from Argentinean hospitals. Antimicrob. Agents Chemother. 47, 3945-3949. doi: 10.1128/AAC.47.12.3945-3949.2003

Baharoglu, Z., Bikard, D., and Mazel, D. (2010). Conjugative DNA transfer induces the bacterial SOS response and promotes antibiotic resistance development through integron activation. PLoS Genet. 6:e1001165. doi: 10.1371/journal.pgen.1001165

Carattoli, A. (2013). Plasmids and the spread of resistance. Int. J. Med. Microbiol. 303, 298-304. doi: 10.1016/j.ijmm.2013.02.001

Carattoli, A., Bertini, A., Villa, L., Falbo, V., Hopkins, K. L., and Threlfall, E. J. (2005). Identification of plasmids by PCR-based replicon typing. J. Microbiol. Methods 63, 219-228. doi: 10.1016/j.mimet.2005.03.018

Clermont, O., Bonacorsi, S., and Bingen, E. (2000). Rapid and simple determination of the Escherichia coli phylogenetic group. Appl. Environ. Microbiol. 66, 4555-4558. doi: 10.1128/AEM.66.10.4555-4558.2000

CLSI, (2012). Performance Standars for Antimicrobial Susceptability Testing. Document M100-S22. Wayne, PA: CLSI.

Curiao, T., Cantón, R., Garcillán-Barcia, M. P., De La Cruz, F., Baquero, F., and Coque, T. M. (2011). Association of composite IS26-sul3 elements with highly transmissible IncI1 plasmids in extended-spectrum-beta-lactamaseproducing Escherichia coli clones from humans. Antimicrob. Agents Chemother. 55, 2451-2457. doi: 10.1128/AAC.01448-10

Davies, J., and Davies, D. (2010). Origins and evolution of antibiotic resistance. Microbiol. Mol. Biol. Rev. 74, 417-433. doi: 10.1128/MMBR. 00016-10

Dolejska, M., Bierosova, B., Kohoutová, L., Literak, I., and Cizek, A. (2009). Antibiotic-resistant Salmonella and Escherichia coli isolates with integrons and extended-spectrum beta-lactamases in surface water and sympatric black-headed gulls. J. Appl. Microbiol. 106, 1941-1950. doi: 10.1111/j.13652672.2009.04155.x

Dolejska, M., Cizek, A., and Literak, I. (2007). High prevalence of antimicrobialresistant genes and integrons in Escherichia coli isolates from Black-headed Gulls in the Czech Republic. J. Appl. Microbiol. 103, 11-19. doi: 10.1111/j.13652672.2006.03241.x

Figueira, V., Serra, E., and Manaia, C. M. (2011). Differential patterns of antimicrobial resistance in population subsets of Escherichia coli isolated from waste- and surface waters. Sci. Total Environ. 409, 1017-1023. doi: 10.1016/j.scitotenv.2010.12.011

Goldstein, C., Lee, M. D., Sanchez, S., Hudson, C., Phillips, B., Register, B., et al. (2001). Incidence of class 1 and 2 integrases in clinical and commensal bacteria from livestock, companion animals, and exotics. Antimicrob. Agents Chemother. 45, 723-726. doi: 10.1128/AAC.45.3.723-726.2001

Guentzel, M. N. (1996). "Escherichia, klebsiella, enterobacter, serratia, citrobacter, and proteus," in Medical Microbiology, 4th Edn., ed S. Baron (Galveston, TX: University of Texas Medical).

Hernandez, J., Johansson, A., Stedt, J., Bengtsson, S., Porczak, A., Granholm, S., et al. (2013). Characterization and comparison of extended-spectrum betalactamase (ESBL) resistance genotypes and population structure of Escherichia coli isolated from Franklin's gulls (Leucophaeus pipixcan) and humans in Chile. PLoS ONE 8:e76150. doi: 10.1371/journal.pone.0076150
Heuer, H., and Smalla, K. (2007). Manure and sulfadiazine synergistically increased bacterial antibiotic resistance in soil over at least two months. Environ. Microbiol. 9, 657-666. doi: 10.1111/j.1462-2920.2006.01185.x

Jové, T., Da Re, S., Denis, F., Mazel, D., and Ploy, M. C. (2010). Inverse correlation between promoter strength and excision activity in class 1 integrons. PLoS Genet. 6:e1000793. doi: 10.1371/journal.pgen.1000793

Kmet, V., Drugdova, Z., Kmetova, M., and Stanko, M. (2013). Virulence and antibiotic resistance of Escherichia coli isolated from rooks. Ann. Agric. Environ. Med. 20, 273-275.

Kraft, C. A., Timbury, M. C., and Platt, D. J. (1986). Distribution and genetic location of $\operatorname{Tn} 7$ in trimethoprim-resistant Escherichia coli. J. Med. Microbiol. 22, 125-131. doi: 10.1099/00222615-22-2-125

Levesque, C., Piche, L., Larose, C., and Roy, P. H. (1995). PCR mapping of integrons reveals several novel combinations of resistance genes. Antimicrob. Agents Chemother. 39, 185-191. doi: 10.1128/AAC.39.1.185

Moura, A., Henriques, I., Ribeiro, R., and Correia, A. (2007). Prevalence and characterization of integrons from bacteria isolated from a slaughterhouse wastewater treatment plant. J. Antimicrob. Chemother. 60, 1243-1250. doi: $10.1093 / \mathrm{jac} / \mathrm{dkm} 340$

Moura, A., Jové, T., Ploy, M. C., Henriques, I., and Correia, A. (2012c). Diversity of gene cassette promoters in class 1 integrons from wastewater environments. Appl. Environ. Microbiol. 78, 5413-5416. doi: 10.1128/AEM.00042-12

Moura, A., Oliveira, C., Henriques, I., Smalla, K., and Correia, A. (2012a). Broad diversity of conjugative plasmids in integron-carrying bacteria from wastewater environments. FEMS Microbiol. Lett. 330, 157-164. doi: 10.1111/j.15746968.2012.02544.x

Moura, A., Pereira, P., Henriques, I., and Correia, A. (2012b). Novel gene cassettes and integrons in antibiotic resistant bacteria isolated from urban wastewaters. Res. Microbiol. 163, 92-100. doi: 10.1016/j.resmic.2011.10.010

Moura, A., Soares, M., Pereira, C., Leitão, N., Henriques, I., and Correia, A. (2009). INTEGRALL: a database and search engine for integrons, integrases and gene cassettes. Bioinformatics 25, 1096-1098. doi: 10.1093/bioinformatics/ btp 105

Pérez-Moreno, M. O., Picó-Plana, E., De Toro, M., Grande-Armas, J., QuilesFortuny, V., Pons, M. J., et al. (2013). Beta-lactamases, transferable quinolone resistance determinants, and class 1 integron-mediated antimicrobial resistance in human clinical Salmonella enterica isolates of non-Typhimurium serotypes. Int. J. Med. Microbiol. 303, 25-31. doi: 10.1016/j.ijmm.2012.11.003

Perry, J. A., and Wright, G. D. (2013). The antibiotic resistance "mobilome": searching for the link between environment and clinic. Front. Microbiol. 4:138. doi 10.3389/fmicb.2013.00138

Poeta, P., Radhouani, H., Igrejas, G., Goncalves, A., Carvalho, C., Rodrigues, J., et al. (2008). Seagulls of the Berlengas natural reserve of Portugal as carriers of fecal Escherichia coli harboring CTX-M and TEM extended-spectrum beta-lactamases. Appl. Environ. Microbiol. 74, 7439-7441. doi: 10.1128/AEM. 00949-08

Poirel, L., Potron, A., De La Cuesta, C., Cleary, T., Nordmann, P., and MunozPrice, L. S. (2012). Wild coastline birds as reservoirs of broad-spectrum-betalactamase-producing Enterobacteriaceae in Miami Beach, Florida. Antimicrob. Agents Chemother. 56, 2756-2758. doi: 10.1128/AAC.05982-11

Post, V., Recchia, G. D., and Hall, R. M. (2007). Detection of gene cassettes in Tn402-like class 1 integrons. Antimicrob. Agents Chemother. 51, 3467-3468. doi: 10.1128/AAC.00220-07

Radhouani, H., Poeta, P., Igrejas, G., Goncalves, A., Vinue, L., and Torres, C. (2009). Antimicrobial resistance and phylogenetic groups in isolates of Escherichia coli from seagulls at the Berlengas nature reserve. Vet. Rec. 165, 138-142. doi: 10.1136/vr.165.5.138

Randall, L. P., Cooles, S. W., Osborn, M. K., Piddock, L. J., and Woodward, M. J. (2004). Antibiotic resistance genes, integrons and multiple antibiotic resistance in thirty-five serotypes of Salmonella enterica isolated from humans and animals in the UK. J. Antimicrob. Chemother. 53, 208-216. doi: 10.1093/jac/dkh070

Sáenz, Y., Vinué, L., Ruiz, E., Somalo, S., Martínez, S., Rojo-Bezares, B., et al. (2010). Class 1 integrons lacking qacEdeltal and sull genes in Escherichia coli isolates of food, animal and human origins. Vet. Microbiol. 144, 493-497. doi: 10.1016/j.vetmic.2010.01.026

Sandvang, D., Aarestrup, F. M., and Jensen, L. B. (1997). Characterisation of integrons and antibiotic resistance genes in Danish multiresistant Salmonella enterica Typhimurium DT104. FEMS Microbiol. Lett. 157, 177-181. doi: 10.1111/j.1574-6968.1998.tb12887.x 
Santos, T., Silva, N., Igrejas, G., Rodrigues, P., Micael, J., Rodrigues, T., et al. (2013). Dissemination of antibiotic resistant Enterococcus spp. and Escherichia coli from wild birds of Azores Archipelago. Anaerobe 24, 25-31. doi: 10.1016/j.anaerobe.2013.09.004

Siguier, P., Perochon, J., Lestrade, L., Mahillon, J., and Chandler, M. (2006). ISfinder: the reference centre for bacterial insertion sequences. Nucleic Acids Res. 34, D32-D36. doi: 10.1093/nar/gkj014

Smalla, K., Haines, A. S., Jones, K., Krögerrecklenfort, E., Heuer, H., Schloter, M., et al. (2006). Increased abundance of IncP-1beta plasmids and mercury resistance genes in mercury-polluted river sediments: first discovery of IncP-1beta plasmids with a complex mer transposon as the sole accessory element. Appl. Environ. Microbiol. 72, 7253-7259. doi: 10.1128/AEM. 00922-06

Soufi, L., Abbassi, M. S., Saenz, Y., Vinue, L., Somalo, S., Zarazaga, M., et al. (2009). Prevalence and diversity of integrons and associated resistance genes in Escherichia coli isolates from poultry meat in Tunisia. Foodborne Pathog. Dis. 6, 1067-1073. doi: 10.1089/fpd.2009.0284

Stokes, H. W., and Hall, R. M. (1989). A novel family of potentially mobile DNA elements encoding site-specific gene-integration functions: integrons. Mol. Microbiol. 3, 1669-1683. doi: 10.1111/j.1365-2958.1989.tb 00153.x

Tacão, M., Correia, A., and Henriques, I. (2012). Resistance to broad-spectrum antibiotics in aquatic systems: anthropogenic activities modulate the dissemination of bla ${ }_{C T X-M}$-like genes. Appl. Environ. Microbiol. 78, 4134-4140. doi: 10.1128/AEM.00359-12

Tacão, M., Correia, A., and Henriques, I. (2013). Environmental Shewanella xiamenensis strains that carry $b l a_{O X A-48}$ or $b l a_{O X A-204}$ genes: additional proof for bla $a_{O X A-48}$-like gene origin. Antimicrob. Agents Chemother. 57, 6399-6400. doi: 10.1128/AAC.00771-13

Tacão, M., Moura, A., Correia, A., and Henriques, I. (2014). Co-resistance to different classes of antibiotics among ESBL-producers from aquatic systems. Water Res. 48, 100-107. doi: 10.1016/j.watres.2013.09.021

Tenaillon, O., Skurnik, D., Picard, B., and Denamur, E. (2010). The population genetics of commensal Escherichia coli. Nat. Rev. Microbiol. 8, 207-217. doi: $10.1038 /$ nrmicro2298
Touchon, M., Hoede, C., Tenaillon, O., Barbe, V., Baeriswyl, S., Bidet, P., et al. (2009). Organised genome dynamics in the Escherichia coli species results in highly diverse adaptive paths. PLoS Genet. 5:e1000344. doi: 10.1371/journal.pgen.1000344

Van Elsas, J. D., Semenov, A. V., Costa, R., and Trevors, J. T. (2011). Survival of Escherichia coli in the environment: fundamental and public health aspects. ISME J. 5, 173-183. doi: 10.1038/ismej.2010.80

Veldman, K., Van Tulden, P., Kant, A., Testerink, J., and Mevius, D. (2013). Characteristics of cefotaxime resistant E. coli from wild birds in The Netherlands. Appl. Environ. Microbio. 79, 7556-7561. doi: 10.1128/AEM. 01880-13

Versalovic, J., Koeuth, T., and Lupski, J. R. (1991). Distribution of repetitive DNA sequences in eubacteria and application to fingerprinting of bacterial genomes. Nucleic Acids Res. 19, 6823-6831.

White, P. A., Mciver, C. J., and Rawlinson, W. D. (2001). Integrons and gene cassettes in the enterobacteriaceae. Antimicrob. Agents Chemother. 45, 2658-2661. doi: 10.1128/AAC.45.9.2658-2661.2001

Conflict of Interest Statement: The authors declare that the research was conducted in the absence of any commercial or financial relationships that could be construed as a potential conflict of interest.

Received: 25 March 2014; accepted: 23 July 2014; published online: 12 August 2014. Citation: Moura A, Araújo S, Alves MS, Henriques I, Pereira A and Correia ACM (2014) The contribution of Escherichia coli from human and animal sources to the integron gene pool in coastal waters. Front. Microbiol. 5:419. doi: 10.3389/fmicb. 2014.00419

This article was submitted to Evolutionary and Genomic Microbiology, a section of the journal Frontiers in Microbiology.

Copyright (C) 2014 Moura, Araújo, Alves, Henriques, Pereira and Correia. This is an open-access article distributed under the terms of the Creative Commons Attribution License (CC BY). The use, distribution or reproduction in other forums is permitted, provided the original author(s) or licensor are credited and that the original publication in this journal is cited, in accordance with accepted academic practice. No use, distribution or reproduction is permitted which does not comply with these terms. 